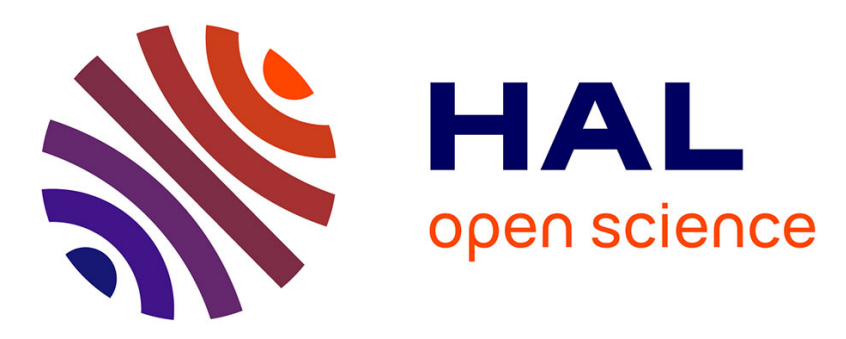

\title{
Integration of Social Concerns in Collaborative Logistics and Transportation Networks
}

Ridha Derrouiche, Abdelhamid Moutaoukil, Gilles Neubert

\section{To cite this version:}

Ridha Derrouiche, Abdelhamid Moutaoukil, Gilles Neubert. Integration of Social Concerns in Collaborative Logistics and Transportation Networks. 15th Working Conference on Virtual Enterprises (PROVE), Oct 2014, Amsterdam, Netherlands. pp.730-738, 10.1007/978-3-662-44745-1_72 . hal01392181

\section{HAL Id: hal-01392181 \\ https://hal.inria.fr/hal-01392181}

Submitted on 4 Nov 2016

HAL is a multi-disciplinary open access archive for the deposit and dissemination of scientific research documents, whether they are published or not. The documents may come from teaching and research institutions in France or abroad, or from public or private research centers.
L'archive ouverte pluridisciplinaire HAL, est destinée au dépôt et à la diffusion de documents scientifiques de niveau recherche, publiés ou non, émanant des établissements d'enseignement et de recherche français ou étrangers, des laboratoires publics ou privés.

\section{(c)(1)}

Distributed under a Creative Commons Attribution| 4.0 International License 


\title{
Integration of Social Concerns in Collaborative Logistics and Transportation Networks
}

\author{
Ridha Derrouiche ${ }^{1}$, Abdelhamid Moutaoukil ${ }^{2}$ and Gilles Neubert ${ }^{1}$ \\ ${ }^{1}$ UMR-5600, ESC-SE, 51-53 cours Fauriel BP29 - 42000 Saint-Etienne, France \\ ${ }^{2}$ Institut Fayol- UMR-5600, EMSE, 158 cours fauriel, Saint-Etienne, France.
}

\begin{abstract}
Freight transport optimization, long based solely on an economic approach, happen today through the integration of environmental and/or social concerns, in line with the objectives of sustainable development. In the case of Small and Very Small Enterprises, these objectives cannot be reached individually, and these companies have to join their efforts to find collective solutions. Therefore, the Fleet Size and Mix Vehicle Routing Problem (FSMVRP) was adapted to take into account social objectives, and results are compared to Vehicle Routing Problem with homogeneous fleet. An exact mathematical formulation of the extended problem was developed. Computational experiments for the problem formulation are performed using CPLEX and give a solution of a small instance to illustrate the problem. The model is tested on a case study of optimal parcel pickup, from many manufacturers to a common depot in the agri-food sector.
\end{abstract}

Keywords: Sustainable logistics network; collaborative network; Social concerns; Products pickup optimization; agri-food sector;

\section{Introduction}

The topic of Sustainable Collaborative Networks has been of great interest for the last decade both from academics and practitioners. In this context, logistics systems must now meet the requirements of sustainable development, namely: economic; environmental and social issues. These requirements are more difficult to reach for SMEs, because their logistics performance does not allow them to engage in a sustainable approach [1] [2]. Furthermore, Just in Time-JIT policy has been implemented in most sectors: to deliver faster, more frequently, and in small quantities. These changes in flow management explode the logistics' costs for SMEs, which endangers the entire implementation of a sustainable development approach. For this reason, collaboration has become one of the key issues in supply chain efficiency, in which optimization approaches are expected to play a crucial role [3]. In the French agri-food sector, transportation costs represent about $20 \%$ of the final cost which then emphasizes the importance of the Vehicle Routing Problem-VRP [4].

The objective of this research is to optimize the upstream logistic cost of a common depot of a set of SMEs in the agri-food sector. Depending on the sum of products to be picked up from these manufacturers, the fleet of vehicles has to be adapted in order to reduce the total costs. In addition, these agri-food manufacturers want to include sustainability into their logistics performance, as this would enable them to enhance their brand in the current market, and meet upcoming regulations. Thus, the problem 
considered in this paper is a Fleet Size and Mix Vehicle Routing Problem (FSMVRP) that is adapted to take into account the social objectives, while focusing on the picking up of products from several manufacturers, within logistics network collaboration.

\section{FSMVRP Problem: Definition and Overview}

To enhance an effective collaboration in a logistics network of products pickup or deliveries, the use of vehicles routing remains among the least costly scenarios of collaboration [4]. Most of the time, VRP is based on a combination of "fleet acquisition", "depreciation costs" and "transportation costs" for the routing plan [5]. Logistics planning is a multifaceted field with an increasing complexity in the decisionmaking process [6]. The traditional VRP is usually based on a homogeneous fleet size problem and many researchers have used these assumptions [7]. However, VRP becomes more complex when the vehicle fleet is heterogeneous, i.e., vehicles differ in their equipment, capacity, and cost [8]. In real life, this configuration has multiple advantages. Indeed, the fleet composition can be revised to better suit customer needs [9]. Therefore, vehicles of different carrying capacities provide capacity according to the customers' varying demand, in a more cost effective way [10]. Moreover, it is possible that customers on efficient route may require smaller vehicles to access urban areas, avoid physical restrictions on vehicle size and weight. The reverse may be true in some case for larger vehicles [11]. This field of research is still in full swing because of the large growth in vehicle types and the implementation of new types of constraints on this type of problems [6].

A thorough analysis of the literature shows that almost all papers have addressed the problem only considering the objective of minimizing the economic cost, with the main parameters considered has fixed or variable cost [6]. Few recent scientific studies have also considered the FSMVRP with environmental objective by minimizing the fuel consumption and/or CO2 emissions of vehicle routing [12]. However, social considerations are often neglected and it seems that no scientific work addresses the social dimension in modeling FSMVRP. For this reason, there is a real need to integrate social issue, which will be stated in the following sections. An adequate mathematical decision model will be proposed, tested and validated within a collect pickup case study.

\section{Modeling of Fleet Size and Mix Sustainable Routing Problem}

This section presents a new version of the traditional approach for the FSMVRP. This new model reduces social costs by enhancing the use of different vehicles types.

\subsection{Social concerns to integrate in routing problems}

The secondary effects associated to transport in a logistics network, include accidents, noise, air quality and traffic congestion. Therefore, the adverse social impacts on various stakeholders have to be considered when evaluating sustainable routing systems. Two sorts of stakeholders are mostly involved: carriers and residents. Carriers and especially the drivers involved are the main actors of transport, and their needs and expectations should be taken into account. Any reduction in the number of kilometers traveled, helps reducing the accidental risks. Decreasing congestion by reducing the 
number of vehicles involved in transport also plays a role in reducing the risk of accidents. For our purpose, we chose to use the traveling distance for the accident risk assessment.

The second type of stakeholders is the residents, who are not directly involved in goods transportation, but share the same transport network. Vehicles Congestion, noise as well as blocking access because of parked or blocked trucks, and other situations, are negatively considered by most inhabitants. Thus, a transport system that reduces congestions, or limits the use of large vehicles in transportation grids can be considered as a sustainable solution. Note that all of these indicators are difficult to quantify empirically, because they are linked to more sociological aspects. For this reason, we consider the number and the size (type) of used vehicles as an estimation of other less quantifiable indicators of the social pillar of sustainable development.

\subsection{General Assumptions \& Format definition}

As in normal VRPs, we assume that there is only one depot in our system. The schedules are one-time plans and the time horizon is assumed to be a single period e.g. one day. It is assumed that all goods are conditioned in parcels with different volumes and weights. The fleet consists of vehicles of multiple types with differing curb weights and load capacities. All vehicles start their routes at time zero. Vehicles are assumed to travel with a constant speed that depends on the destination (urban or regional). Each vehicle returns to the depot once completed its respective trips. All waiting times are assumed to be equal to zero and all sorts of unexpected delays are disregarded, that is, a vehicle never becomes inactive until it returns to the depot. At each stop, the vehicle has a loading time which is relative to the vehicle type. Note that we are dealing with a problem of products pickup from manufacturers to a common depot. After loading, vehicles immediately go to their next stop which can either be a new manufacturer or a return trip to the depot.

There is a restriction on the total duration of each route: Vehicles tours have a strict deadline (4 hours in our case), and the arrival time at the depot cannot exceed this deadline. There is limitation on the vehicle speeds, for regional delivery only average vehicle speeds above $45 \mathrm{~km} / \mathrm{h}$ are considered.

Our problem is defined as complete graph $G(N, A)$ where $N=\{0\} U\{1, \ldots, n\} U\{n+1\}$ defines the set of different nodes and $\{0\}$ and $\{n+1\}$ represent the depot and $A$ is the set of arcs between each pair of nodes. The set of manufacturers is represented by $N_{c}$ $=\{1, \ldots, n\}$. For every arc $(i, j)$ in $A$, the distance between nodes $i$ and $j$ is defined as $d_{i j}$. For all $i \in N_{c}$, there is a positive demand of $q_{i}$ to be satisfied. For each manufacturer, there is an associated loading time which is directly proportional to the vehicle type but not to the demand of that manufacturer, because we are dealing with very small demands which are delivered in parcels. The demand at the depot is considered to be zero $\left(q_{0}=0 ; q_{n+1}=0\right)$. An unlimited heterogeneous fleet of vehicles is available. This fleet is composed of $V=\{1, \ldots, K\}$ different vehicle types, each with a different capacity. The following are the constraints used for traditional FSMVRP:

i. Each manufacturer should be visited once by one vehicle.

ii. Routes must start and finish in the depot.

iii. Vehicle capacity should not be exceeded.

3.3 Modeling FSMVRP under social objectives 
Based on the literature, we adopted the formulation of FSMVRP to be consistent with the problem addressed. The following notations are used:

$\boldsymbol{n}=$ number of manufacturers (nodes) $\quad ; \quad \boldsymbol{K}=$ number of vehicle types; $\boldsymbol{Q}_{k}$

$=$ total authorized weight of a type $\mathrm{k}$ vehicle $\left(Q_{l}<\ldots<Q_{K}\right)$;

$\boldsymbol{f}_{\boldsymbol{k}}=$ fixed cost of a type $\mathrm{k}$ vehicle $\left(f_{1}<\ldots<f_{k}\right) ; \quad \boldsymbol{\beta}_{k}=$ cost $/ \mathrm{km}$ of a type $\mathrm{k}$ vehicle;

$\boldsymbol{\alpha}_{k}=$ cost /ton.km of a type k vehicle ; $\boldsymbol{\delta}_{k}=$ cost /ton of a type k vehicle;

$\boldsymbol{C}_{\boldsymbol{k}}^{\boldsymbol{P}}=$ capacity (useful load) of a type $k$ vehicle $\quad ; \quad \boldsymbol{q}_{\boldsymbol{i}}=$ demand for customer $i ;$

$\boldsymbol{E}_{\text {empty }}^{\boldsymbol{k}}=\mathrm{CO}_{2}$ emission of an empty vehicle of type $k ; \boldsymbol{d}_{\boldsymbol{i j}}=$ distance of the arc $i j$;

$\boldsymbol{E}_{\text {full }}^{\boldsymbol{k}}=\mathrm{CO}_{2}$ emission of full truckload of type $k$ vehicle;

$\boldsymbol{E}_{\text {manufacturing }}(\boldsymbol{k})=\mathrm{CO}_{2}$ emission of manufacturing type $k$ vehicle;

$\boldsymbol{D}(\boldsymbol{k})=$ Lifetime in $\mathrm{km}$ of type $k$ vehicle;

$\boldsymbol{T}=$ Vehicle routes deadline $\quad ; \quad \boldsymbol{t}^{k}=$ Unloading time of type $k$ vehicle;

In addition, the following decision variables are used:

$\boldsymbol{y}_{i j}^{\boldsymbol{k}}$ : flows on $\operatorname{arcs}(i, j)$ loaded on type $k$ vehicle;

$\boldsymbol{Z}_{\boldsymbol{j}}^{\boldsymbol{k}}: 1$ if type $k$ vehicle visit $j$, and 0 otherwise; $\boldsymbol{t}_{\boldsymbol{i j}}$ : Time runs on $(i, j)$;

$x_{i j}^{k}: 1$ if type $k$ vehicle is assigned to $(i, j)$, and 0 otherwise;

An infinite set of each vehicle type is assumed. The sum $\sum_{j=1}^{N} x_{0 j}^{k}$ represents the number of vehicles of type $k$ used. Generally, to incorporate sustainable aspects, we concentrate on these fours factors: the type and the number of vehicles used, cargo load and the distance traveled. Then the objective function (1) is defined as follow:

$$
\text { Minimize } \sum_{j=1}^{N} Q_{k} x_{0 j}^{k} * \sum_{k \in V} \sum_{(i, j) \in A} d_{i j} x_{i j}^{k}
$$

To assess economic and environmental costs of social optimization solutions, we adopted these equations:

- $\quad$ Environmental function $\left(\mathrm{CO}_{2}\right.$ emissions):

$\begin{aligned} & \boldsymbol{\varepsilon}(g)=\sum_{\substack{k \in V \\ \text { Economic function: }}} \sum_{\substack{(i, j) \in A \\ \text { - }}} d_{i j} *\left[\left(\boldsymbol{E}_{\text {full }}^{k}-\boldsymbol{E}_{\text {empty }}^{k}\right) * \frac{y_{i j}^{k}}{\boldsymbol{C}_{\boldsymbol{k}}^{P}}+\boldsymbol{E}_{\text {empty }}^{k}+\frac{\boldsymbol{E}_{\text {manufacturing }}(k)}{\boldsymbol{D}(\mathrm{k})}\right] \text { (2) } \\ & \text { Ecomic }\end{aligned}$

$$
\begin{aligned}
\operatorname{Cost}(€)=\sum_{k \in V} \sum_{j \in N} f_{k} x_{0 j}^{k}+\sum_{k \in V} \sum_{(i, j) \in A} \alpha_{k} d_{i j} y_{i j}^{k} \\
+\sum_{k \in V} \sum_{(i, j) \in A} \beta_{k} d_{i j} x_{i j}^{k}+\sum_{k \in V} \sum_{(i, j) \in A} \delta_{k} y_{i j}^{k}
\end{aligned}
$$

From literature, all constraints related to a FSMVRP were adapted, and a time constraint was added for routes (constraint 11). So, the constraints brought to our model are as follows: 


$$
\begin{aligned}
& \sum_{i=0}^{n} x_{i j}^{k}=\sum_{i=0}^{n} x_{j i}^{k}, \forall k \in V, \forall j \in N \text { (4) } ; \quad \sum_{i=0}^{n} x_{i j}^{k}=Z_{j}^{k}, \forall k \in V, \forall j \in N(5) \\
& \sum_{k=1}^{m} Z_{j}^{k}=1, \forall j \in N c \quad \text { (6); } \quad ; \quad \sum_{j \in N} y_{0 j}^{k}=0 \\
& \sum_{k \in V} \sum_{j \in N} y_{j \mathbf{0}}^{k}=\sum_{i \in N} q_{i} \quad \text { (8) } \quad ; \quad y_{i j}^{k} \leq \sum_{k \in V} Q_{k} x_{i j}^{k}, \forall(i, j) \in A \\
& \sum_{i=0}^{n} y_{i j}^{k}+q_{j} * Z_{j}^{k}=\sum_{i=0}^{n} y_{j i}^{k} \quad \forall k \in V, \forall j \in N c \text { (10) } \\
& t^{k} \sum_{(i, j) \epsilon A}^{n} x_{i j}^{k}+\sum_{(i, j) \epsilon A}^{n} t_{j i} x_{j i}^{k} \leq T \quad, \forall k \in V \quad \text { (11) } \\
& y_{i j}^{k} \geq 0 ; \quad t_{i j} \geq 0 \quad \forall(i, j) \in A \forall k \in V(12) ; \quad y_{i i}^{k}=0, \quad \forall i \in N, \forall k \in V \\
& x_{i j}^{k} \in\{0,1\}, \quad \forall(i, j) \in A, \forall k \in K \quad(14) \quad ; \quad Z_{i}^{k} \in\{0,1\}, \quad \forall i \in A, \forall k \in K
\end{aligned}
$$

Constraint (4) ensure that a vehicle that arrives at a manufacturer will also be the same type that leaves, while constraints (5) and (6) state that each manufacturer is visited exactly once, so the type of vehicle arriving and leaving one particular manufacturer has to be the same. Constraints (7) and (8) indicate that vehicles are empty when they leave the depot and must return loaded. In (9), the total load on a trip is constrained not to exceed the capacity of the vehicle assigned to that trip and equation (10) represents the movement of goods assuming that all manufacturer demands must be satisfied. The constraint of max time of a route is represented in (11). Constraints (12) ensures that the flow and time are non-negative and (13) means that there is no flow from a manufacturers to itself; finally constraints (14) and (15) define that each arc has the value 1 if it is used and 0 if it is not used by a vehicle of type $k$.

\section{Case Study}

In order to test the model, one of our professional collaborators (3PL) gave us the following case study. A common platform (depot) located in Saint-Etienne processes every day parcels pickup from different manufacturers. In a given day, 10 addresses are serviced in the Loire region in France. The demand vector is given by table 1:

Table.1. Manufacturer's demand

\begin{tabular}{|l|c|c|c|c|c|c|c|c|c|c|}
\hline Manufacturer & 1 & 2 & 3 & 4 & 5 & 6 & 7 & 8 & 9 & 10 \\
\hline Demand (Ton) & 0.09 & 0.11 & 0.07 & 0.5 & 0.7 & 0.03 & 0.11 & 0.06 & 0.05 & 0.6 \\
\hline
\end{tabular}

\subsection{Optimization Approach}

First, our mathematical model was programmed in CPLEX. Then, MAPPOINT software is used to represent manufacturers and depot locations geographically. Then, the software provides a distance matrix between the various locations according to their address. Then, this distance matrix with other data from the case study is introduced in our model via the optimization software CPLEX. The execution of our optimization program provides the optimal delivery routes depending on selected objective (economic, environmental or social). After that, all scenarios can be represented geographically in MAPPOINT software. To operate our case study, we used a set of parameters, summarized in the table 2.

Table.2. Parameters of optimization (adapted from [13] and [14]) 


\begin{tabular}{|c|c|c|c|c|c|c|c|c|c|c|}
\hline 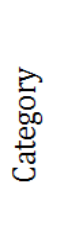 & 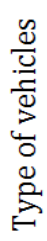 & 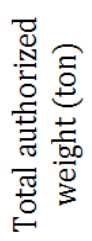 & 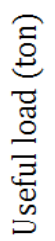 & 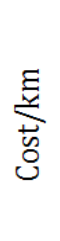 & 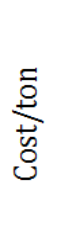 & 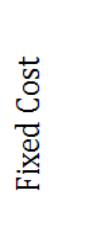 & 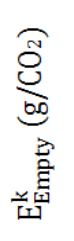 & 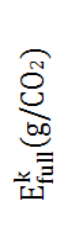 & 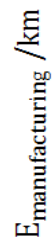 & 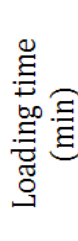 \\
\hline LDV- & 1 & $1.5-2.5$ & 0.7 & 0.15 & 0.04 & 104.84 & 68.4 & 68.4 & 8.3 & 7 \\
\hline HDV -. & 2 & 3.5 & 1.4 & 0.23 & 0.05 & 111.58 & 100.9 & 101 & 10.5 & 10 \\
\hline HDV -. & 3 & $5-6$ & 2.84 & 0.25 & 0.07 & 111.58 & 107 & 154 & 14.2 & 17 \\
\hline
\end{tabular}

\subsection{Results}

In this case study and depending on fleet composition, the social optimization model presents the following results for direct pickup scenario (DC) and for social VRP:

Table.3. Summary of results

\begin{tabular}{|c|c|c|c|c|c|c|}
\hline & \multirow{4}{*}{ Fleet } & \multirow{4}{*}{$\begin{array}{c}D C \\
\text { Type 1 } \\
\text { (Best fleet) }\end{array}$} & & & & \\
\hline & & & \multicolumn{4}{|c|}{ Social VRP } \\
\hline & & & Heterogeneous & \multicolumn{3}{|c|}{ Homogeneous } \\
\hline & & & Type $(1 ; 2 ; 3)$ & Type 1 & Type 2 & Type 3 \\
\hline \multirow{5}{*}{ 离 } & Economic & 262.2 & 105.8 & 129.55 & $\begin{array}{c}91.15 \\
8\end{array}$ & 117.38 \\
\hline & Environmental & 17106 & 12132 & 11252 & 13680 & 14297 \\
\hline & Social & 4460.6 & 452.05 & 1173.6 & 859.39 & 1225.9 \\
\hline & Distance & 223.03 & 111.45 & 146.7 & 122.77 & $\begin{array}{c}111.4 \\
5\end{array}$ \\
\hline & $\begin{array}{c}\text { Number of } \\
\text { routes }\end{array}$ & 10 & $\begin{array}{l}2: 1 \text { of type } 1 \\
\text { and } 1 \text { of type } 3\end{array}$ & 4 & 2 & 2 \\
\hline
\end{tabular}

Routes relevant to the use of different fleets are summarized in the following table:

Table.4. Routes of various scenarios

\begin{tabular}{|c|c|l|}
\hline Fleet & Composition & \multicolumn{1}{c|}{ Routes } \\
\hline \multirow{3}{*}{$\begin{array}{c}\text { Homoge- } \\
\text { neous }\end{array}$} & Type 1 & $\begin{array}{l}\text { Route 1: }(0,5,0) ; \text { Route } 2:(0,10,0) ; \\
\text { Route 3: }(0,1,4,3,0) ; \text { Route } 4:(0,9,2,8,6,7,0) ;\end{array}$ \\
\cline { 2 - 3 } & Type 2 & $\begin{array}{l}\text { Route } 1:(0,2,7,6,8,5,0) ; \text { Route } 2: \\
(0,9,3,1,4,10,0)\end{array}$ \\
\cline { 2 - 3 } & \multirow{2}{*}{ Type 3 } & $\begin{array}{l}\text { Route } 1:(0,9,3,1,4,10,5,0) ; \text { Route 2: } \\
(0,2,8,7,6,0)\end{array}$ \\
\hline \multirow{2}{*}{$\begin{array}{c}\text { Hetero- } \\
\text { geneous }\end{array}$} & \multirow{2}{*}{ Type (1; 2; 3) } & Type 1: Route 1 $(0,2,6,7,8,0)$ \\
\cline { 3 - 3 } & & Type 2: No Route $($ Type not used $)$ \\
\cline { 3 - 3 } & & Type 3: Route 1: $(0,9,3,1,4,10,5,0)$ \\
\hline
\end{tabular}

For the discussed case study, the model gives different results depending on the fleet composition. First, the basic scenario with direct pickup (DC) from the manufacturers to the depot has to be assessed. In direct pickup scenario, the use of a homogeneous 
fleet of type 1 vehicles gives better results than homogeneous fleets that consist sequentially of type 2 and type 3 vehicles.

The second finding is that social optimization for vehicle routing gives best results than direct pickup scenario, whatever the composition of the fleet used and whatever the assessment criterion. This is explained by the fact that direct pickup scenario requires more vehicles (10 vehicles) and travels longer distances.

The third important point with this model is that the use of a heterogeneous fleet gives the best social results and a good compromise of economic and environmental cost than the use of homogeneous fleet. Indeed, the use of a homogeneous fleet of type 2 vehicles significantly decreases the economic cost, but explodes at the same time the environmental and social costs. And in the same way, using a fleet of type 1 vehicles reduces the environmental cost but not the economic and social costs. While the scenario using a homogeneous fleet of type 3 vehicles, dramatically increase all costs (economic, environmental and social) because it uses 2 large vehicles, despite the fact that it travels the same distance as the scenario with a heterogeneous fleet. Using a heterogeneous fleet can sometimes substitute a large truck with a low fill rate, by a full small truck. Thus minimizes the economic cost while generating fewer $\mathrm{CO} 2$ emissions, less noise and less congestion.

Another observation concerning social optimization is that the routes to follow depend on the fleet composition. Thus, the use of a fleet with type 2 vehicles or with type 3 vehicles requires 2 routes, but in the first case, travels are $122.77 \mathrm{~km}$ long while in the second cases, travels are only $111.45 \mathrm{~km}$ long. This is explained by the fact that routes depend on the vehicles capacity of the fleet used.

\section{Conclusion}

The optimization of freight distribution for SMEs needs an improved shared logistics network to meet the requirements of sustainable development and therefore, the performance of their upstream logistics are not in line with the social objectives.

In this paper, the pickup network was designed with a single platform (collect center) and the routing problem was solved taking into consideration the social pillar of sustainable development. Due to the constraints of low volume and limited time for delivery, the Fleet Size and Mix Vehicle Routing Problem (FSMVRP) was studied. Starting from the literature on this topic, new social objective functions were developed to minimize the traveled distance and the number and the size of the vehicles used to reduce the risk of accidents, congestion and noise.

The aim of this paper is to demonstrate the importance of the choice of the type and number of vehicles in social optimization, and that routes depend on fleet composition. A linear multi-objective programming optimization model was developed that compare optimal social solutions depending on the fleet composition. Unfortunately, due to long computational delays, this model can support only small instances. Clearly, this difficulty should be dealt with in future work. Our work, as presented, represents the first step to designing shared logistics schemes that fulfill the requirements of sustainable development. 


\section{Acknowledgment}

Authors would like to thank Region Rhône-Alpes for its financial support (Research Cluster GOSPI-ARC8).

\section{References}

1. Conservatoire National des Arts et Métiers (CNAM).: Enquête Nationale : La logistique dans les PME-PMI de l'agroalimentaire, synthèse des résultats. Chaire de Logistique, Transport, Tourisme. (2007)

2. Pôle Agroalimentaire Loire,: Organisation logistique du secteur agroalimentaire dans la Loire. (2011)

3. Creazza, A., Dallari, F., Rossi, T., 2012. Applying an integrated logistics network design and optimisation model: the Pirelli Tyre case. International Journal of Production Research 50, 3021-3038.

4. Moutaoukil, A., Derrouiche, R., Neubert, G., 2013. Modeling a Logistics Pooling Strategy for Agri-Food SMEs, in: Camarinha-Matos, L.M., Scherer, R.J. (Eds.), Collaborative Systems for Reindustrialization, IFIP Advances in Information and Communication Technology. Springer Berlin Heidelberg, pp. 621-630.

5. Hoff, A., Andersson, H., Christiansen, M., Hasle, G., Løkketangen, A., 2010. Industrial aspects and literature survey: Fleet composition and routing. Computers \& Operations Research 37, 2041-2061.

6. Pasha, U., Hoff, A., Løkketangen, A., 2013. The Shrinking and Expanding Heuristic for the Fleet Size and Mix Vehicle Routing Problem. Scientific Letters, University of Zilina, pp. 6-13.

7. Hasle, G., Kloster, O., 2007. Industrial Vehicle Routing, In: Quak, E. (Eds.), Geometric Modelling, Numerical Simulation, and Optimization. Springer Berlin Heidelberg, pp. 397-435.

8. Taillard, E.D., 1999. A heuristic column generation method for the heterogeneous fleet Vehicle Routing Problem. RAIRO - Operations Research 33, 1-14.

9. Bräysy, O., Dullaert, W., Hasle, G., Mester, D., Gendreau, M., 2008. An Effective Multirestart Deterministic Annealing Metaheuristic for the Fleet Size and Mix Vehicle-Routing Problem with Time Windows. Transportation Science 42, 371386.

10. Tarantilis, C.D., Kiranoudis, C.T., Vassiliadis, V.S., 2004. A threshold accepting metaheuristic for the heterogeneous fixed fleet VRP. European Journal of Operational Research 152, 148-158.

11. Semet, F., 1995. A two-phase algorithm for the partial accessibility constrained vehicle routing problem. Ann Oper Res 61, 45-65.

12. Kopfer, H.W., Schönberger, J., Kopfer, H., 2014. Reducing greenhouse gas emissions of a heterogeneous vehicle fleet. Flex Serv Manuf J 26, 221-248.

13. Jancovici, M., 2007. Temis - Bilan carbone. Guide des facteurs d'émissions - Calcul des facteurs d'émissions et sources bibliographiques utilisées. (Monographie). ADEME France, Paris, France.

14. Hickman, J., Hassel, D., Joumard, R., Samaras, Z., Sorenson, S., 1999. Methodology for calculating transport emissions and energy consumption. 